\title{
Low population density of a tropical forest carnivore, Cryptoprocta ferox: implications for protected area management
}

\author{
Clare E. Hawkins and Paul A. Racey
}

\begin{abstract}
The widespread geographical distributions of mammalian carnivores such as the Carnivora and the Dasyuridae have often been erroneously equated with abundance. Their low densities and high demands on habitat area can render mammalian carnivores especially vulnerable to habitat fragmentation and destruction. The fossa Cryptoprocta ferox (Viverridae) is a mammalian carnivore threatened by the rapid loss of Madagascar's forests, to which it is endemic. A 3-year mark-recapture study, comprising four censuses, generated an estimate of fossa population density at 0.18 adults $\mathrm{km}^{-2}$, or 0.26 individuals $\mathrm{km}^{-2}$. This was supported by a similar estimate from home range data. The fossa is thought to be unusually common in the study area, yet the estimated density was lower than that predicted for a typical tropical carnivorous mammal of the body mass of a fossa. Ecologists are frequently under pressure to provide
\end{abstract}

estimates of local and global population numbers of their study species; we discuss the numerous factors that limit our ability to do this on the basis of a single population estimate. Nonetheless, our findings are sufficient to suggest that none of Madagascar's 46 protected areas supports a viable population of fossas, indicating a demand for corridors and enlarged reserves to ensure this species' long-term survival. Loss of the top predator can have a knock-on effect on an ecosystem. The findings indicate that, to maintain intact tropical forest ecosystems, it may be essential to consider the requirements of their often little-known mammalian carnivores. These requirements could be far greater than previously assumed.

Keywords Carnivore conservation, Cryptoprocta ferox, fossa, habitat fragmentation, Madagascar, markrecapture, population density, protected areas, tropical.

\section{Introduction}

A species may appear numerous if broadly distributed across habitats and geographic regions, but if it is locally rare in all regions then it may be highly vulnerable to extinction (Rabinowitz, 1981; Soulé, 1987). In such species (e.g. African wild dogs Lycaon pictus), populations can be near extinction before the problem is recognized (Fanshawe et al., 1991). This phenomenon is common among carnivorous species, which are typically sparsely distributed and wide-ranging, and therefore especially affected by habitat fragmentation. For tropical forest carnivorous mammals it is particularly difficult to assess the effect of habitat fragmentation, because ecological studies have been carried out on so few species (Schreiber et al., 1989; Schaller, 1996; Ginsberg, 2001).

Madagascar's forests are disappearing quickly $\left(1,170 \mathrm{~km}^{2}\right.$, c. $1 \%$, per year, FAO, 2001 ; or $1,710 \mathrm{~km}^{2}$, c. $2 \%$,

Clare E. Hawkins* and Paul A. Racey (Corresponding author) School of Biological Sciences, University of Aberdeen, Aberdeen, AB24 2TZ, UK. E-mail p.racey@abdn.ac.uk

*Current address: School of Zoology, Private Bag 05, University of Tasmania, Hobart, Tasmania 7001, Australia.

Received 20 February 2004. Revision requested 8 June 2004. Accepted 13 August 2004 per year, Green \& Sussman, 1990, Smith et al., 1997, Parcs Nationaux de Madagascar, 2001), but the immediacy of threat that this represents to carnivores is unknown. The fossa Cryptoprocta ferox is an Endangered (IUCN, 2003), solitary viverrid with both arboreal and terrestrial habits, found in undisturbed forests throughout Madagascar, where it is endemic (Hawkins, 2003). It is the island's largest terrestrial animal species, with a mean body mass of $7.4 \mathrm{~kg}(\mathrm{n}=17, \mathrm{SD}=1.2)$ in males and $6.1 \mathrm{~kg}(\mathrm{n}=11$, SD = 0.6) in females (Hawkins, 1998). The IUCN Mustelid and Viverrid Action Plan recommended field research to assess the population size of the fossa within Madagascar's conservation areas (Schreiber et al., 1989). Its size and highly carnivorous diet (Albignac, 1973; Rasolonandrasana, 1994; Rasoloarison et al., 1995; Hawkins, 1998) suggest that fossa population densities are likely to be lower than those of any other terrestrial species in Madagascar. These populations may therefore be the most sensitive to habitat fragmentation and to the size of protected areas.

This study represents the first attempt to derive population density estimates for the fossa. Such estimates have implications for the conservation of intact ecosystems as well as of individual species. Removal experiments indicate that the loss of a predator typically has strong effects on the structure and dynamics of prey 
communities (Sih et al., 1985). These effects can cascade down the trophic levels, resulting in overgrazing or other biodiversity-reducing phenomena (Pace et al., 1999; Schmitz et al., 2000). Vertebrate carnivores, such as sea otters Enhydra lutris (Estes \& Duggins, 1995), grey wolves Canis lupus (McLaren \& Peterson, 1994) and coyotes Canis latrans (Crooks \& Soulé, 1999), typically exert a stronger such effect than do invertebrate carnivores (Schmitz et al., 2000).

We sought to measure the density of the fossa population in a region of Madagascar where it was considered common, to improve conservation status assessments and to shed light on the size of protected areas required to preserve viable populations of this species.

\section{Methods}

We investigated fossa population density using a markrecapture model. Trapping took place between 1994 and 1996 on a $100 \mathrm{~km}^{2}$ forestry concession, held by the Centre de Formation Professionnelle Forestière de Morondava (CFPF), known as the Kirindy Forest or Kirindy/CFPF (Fig. 1). This concession is not a legally recognized protected area, and distinct from the Kirindy-Mitea National Park further south. The fossa is reported to be particularly common (Albignac, 1973; Schreiber et al., 1989) in the Menabe region, in which Kirindy Forest lies. Menabe is one of the few remaining areas of western dry deciduous forest, and several threatened vertebrates are endemic to the region. This region is rarely clearly defined, but commonly refers to the area bound by the rivers Tsiribihina to the north, Maharivo to the south, and extending c. $100 \mathrm{~km}$ east to Miandrivazo (Fig. 1). Dry deciduous forest was classified as a top priority for conservation in a 1995 workshop defining research and biodiversity conservation needs for Madagascar (Ganzhorn et al., 1997).

Selective logging was carried out in the concession between 1978 and 1993, with no significant effect on the abundance of a wide range of taxa (Ganzhorn et al., 1990; Ganzhorn \& Sorg, 1996). During our study, logging continued only in a small area near the edge of the concession, the forest having been given over primarily to ecotourism and research. The concession was uninhabited, apart from the small logging area, and the main camp occupied by a small number of CFPF personnel, researchers and tourists. We were aware of occasional small-scale hunting of tenrecs Tenrec ecaudatus and sportive lemurs Lepilemur ruficaudatus and, occasionally, the theft of individual trees. Unfortunately, such activities have reportedly increased markedly on the concession since the time of our study.

\section{Trapping}

We carried out four standardized trapping sessions. We placed box traps (collapsible, single door bobcat traps, $107 * 38 * 51 \mathrm{~cm}$; Tomahawk, Wisconsin, USA) on a grid, $500 \mathrm{~m}$ apart, such that each $1 \mathrm{~km}^{2}$ block of forest within the trapping area contained four traps (Fig. 1). To reduce any effect of the numerous old vehicle tracks in the forest, we positioned traps at least $20 \mathrm{~m}$ from any track exceeding $1 \mathrm{~m}$ width, with the majority of traps at least $100 \mathrm{~m}$ from such tracks. The 18 traps used in the study were positioned in 4.5 adjacent $\mathrm{km}^{2}$ blocks, and set for a 3-day period. After this period, we moved them to another

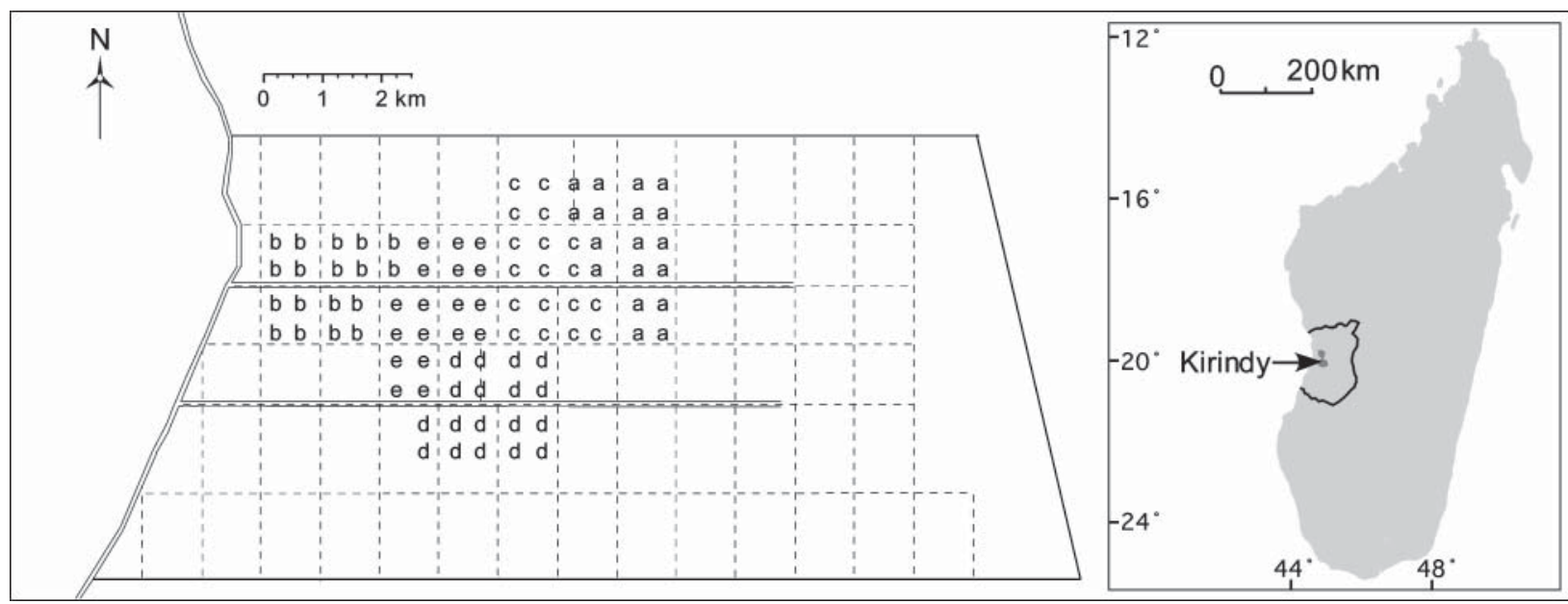

Fig. 1 Trapping sites of each of the five periods that made up a trapping session. Traps were first placed for 3 days on the sites marked 'a', then moved to the sites marked ' $b$ ', and so on. The dotted grid lines delineate the mostly $1 \mathrm{~km}^{2}$ forestry blocks set up in Kirindy. The fine continuous lines represent the main roads in the forest. The dark shaded region on the inset of Madagascar indicates the position of the forested areas around and including Kirindy/CFPF and the outline indicates the approximate borders of the Menabe region. 
4.5 adjacent $\mathrm{km}^{2}$ block. Each trapping session comprised five of these 3-day periods and covered the same $22.5 \mathrm{~km}^{2}$ area. The first session was carried out more slowly (8 weeks in August-September 1994) than the latter three, each of which took 6 weeks, and traps were placed in slightly different groupings. The second and third sessions took place in 1995 (June-July and JulyAugust respectively), with the final trapping session in May-June 1996. Traps were not prebaited because, during initial trials, this had no effect on trapping success. Bait was rotten chicken pieces. All trapping was carried out in the dry season (May-October), as trapping success was negligible in the wet season.

Each trapped fossa was anaesthetized with $5 \mathrm{mg}$ ketamine (Vetalar; Pharmacia \& Upjohn, Corby, UK) and $1 \mathrm{mg}$ xylazine (Rompun; Bayer, Bury St Edmunds, UK) per $\mathrm{kg}$ estimated body weight. For future identification, a Trovan transponder (Usling GmbH, Euskirchen, Germany) was inserted under the skin between the shoulder blades, and a coloured and numbered ear tag (Rototag; Dalton, Henley-on-Thames, UK) fixed in each ear. Afterwards the fossa was left to recover in the trap, with water and food, and released once coordination of movement indicated a full recovery.

Trappability was calculated by examining the occasions when previously captured individuals were confirmed, through subsequent trapping sessions, to be alive and in the area during a certain session.

\section{Radio-tracking}

As an independent density estimate, fossas were radiotracked to provide home range data. If home ranges are exclusive, the inverse value of the range is an estimate of population density. Twelve of the trapped adults were radio-collared with transmitters TW-3 (Biotrack, Wareham, UK) and Mod-335 (Telonics, Mesa, USA). Signals from both transmitter types were consistently detected at distances up to 1,200 $\mathrm{m}$, using radio-receivers (Mariner 57, Lowestoft, UK and Custom Electronics CEI2, Urbana, USA) with aerials (yagi, Biotrack, Wareham, UK and H-antenna, Telonics, Mesa, USA) by vehicle. Radiotracking on foot through areas without roads was impracticable, given the density of much of the vegetation. Fossas were tracked for periods ranging from 6 weeks to 13 months between 1995 and 1996. Fixes were taken a minimum of 8 hours apart, evenly spread across day and night because fossa activity was unaffected by time of day (Hawkins, 1998). As a result of the distribution of the roads in Kirindy and the transmitter signal range, it was possible to radio-track fossas reliably within a total area of $56 \mathrm{~km}^{2}$.

To quantify the error involved in the radio-tracking, six test transmitters were left in places in the forest unknown to the tracker, and the distance of error (E) between the estimated location and the true location was recorded for each. Additionally, two fossas dropped their collars, and the distance between the estimated location (on the first occasion that the collar was recorded in that position) and the true location was also recorded for these. Regression of these data on the mean distance of the tracker from the transmitter (D) gave the equation $\mathrm{E}=0.5 \mathrm{D}-78.0\left(R^{2}=0.888, \mathrm{P}<0.001\right)$. For 10 regularly tracked individuals, the mean tracker-to-fix distance was $570 \mathrm{~m}(\mathrm{SD}=118)$. Application of this value to the regression equation indicated that a mean error of $207 \mathrm{~m}$ could be expected between a fix and the true location of the animal.

Home range area was calculated with the programme Wildtrak (ISIS Innovation Ltd, 1992), using the minimum convex polygon method (MCP). This method was chosen for ease of comparison with other studies, being by far the most frequently used, and being relatively robust when numbers of fixes are low (Harris et al., 1990).

\section{Mark-recapture analysis}

Because the population was open, the Jolly-Seber model (Jolly, 1965; Seber, 1965) was used to estimate population size. Where possible, 95\% confidence limits on the estimates were calculated (Manly, 1984). To calculate population density, the trapped area must be known. The area enclosed by the outermost traps was $16.75 \mathrm{~km}^{2}$, but it was likely that the home ranges of a substantial proportion of animals caught did not lie entirely within this area. The true area covered by the traps was calculated by including an additional boundary strip, the width of the average radius of the average home range of a fossa (Dice, 1938; Kenward, 1985).

The minimum number alive at the time of any one trapping session was calculated by summing the number of animals trapped during that session with any animals not caught that had been previously caught and were recaptured during subsequent sessions (Krebs, 1966).

\section{Results}

In total, 31 individuals were captured. Over the entire 2-year census, a total of 11 adult males, nine adult females, five young males and six young females were caught. Sex ratio appeared to be equal, there being no significant difference between numbers of adult males and females $\left(\chi^{2}=0.1, \mathrm{P}>0.75\right)$.

Trappability was calculated from the nine occasions, involving five adults, when previously captured individuals were confirmed, through subsequent trapping sessions, to be alive and in the area during a certain 
session. Of these, there were four occasions on which the adult in question was caught. This indicated a probability of capturing a specific adult during any one session of $44 \%$, or a median probability per adult of $50 \%$ (interquartile range 0-50\%). Individuals were recaptured within a trapping session on a total of only six occasions, involving five adults, indicating that fossas did not become 'trap-happy'.

\section{Number of individuals in the population}

From the mark-recapture data we calculated an estimate of 17 adults within the trapping area at the time of trapping session two. The two subsequent sessions allowed 95\% confidence limits to be calculated (9-33 adults) (Fig. 2). For this estimate, the brevity of the period between sessions two and three violated an assumption of the Jolly-Seber model (that sampling time is negligible relative to intervals between samples). However, when the data from session three were replaced with those from session four a similar figure of 18 adults was obtained. A second estimate of adult number, at session three, was 12 adults. The minimum number alive, during both sessions two and three, was nine adults.

Juveniles were never recaptured during the standardized trapping sessions, so that results including juveniles were less precise. At session two, the total number of adults and juveniles within the trapping area was estimated as 27 individuals (95\% confidence intervals
13-65 individuals). At session three, the estimate was 17 individuals.

\section{Population density}

To convert population size to population density, we first estimated the trapping area. The boundary strip was calculated from dry season home ranges (because trapping was carried out only in this season) of two males (male one: $16.5 \mathrm{~km}^{2}$, obtained in 1995 from 32 radiotracking fixes, and $10.9 \mathrm{~km}^{2}$, obtained in 1996 from 72 fixes; male two: $27.1 \mathrm{~km}^{2}$, obtained in 1996 from 65 fixes) and one female $\left(9.2 \mathrm{~km}^{2}\right.$, obtained in 1995 from 46 fixes). Other individuals were radio-tracked, but because they could not always be located, their complete home ranges could not be calculated; they regularly travelled outside the area in which their transmitter signals could be received. Because an equal sex ratio was found, male and female ranges were given equal weight in calculating the mean. The radius of the mean home range $\left(14.8 \mathrm{~km}^{2}\right)$ treated as a circle was $2.2 \mathrm{~km}$. This was added as a boundary strip round the area enclosed by traps to give a total estimated trapping area of $83.3 \mathrm{~km}^{2}$.

The mean of the two estimates of population number at sessions two and three respectively (15 adults) gave an estimated population density of 0.18 adults $\mathrm{km}^{-2}$. The same calculation with the data including juveniles (mean 22 individuals) generated a density estimate of 0.26 individuals $\mathrm{km}^{-2}$. The minimum number alive data

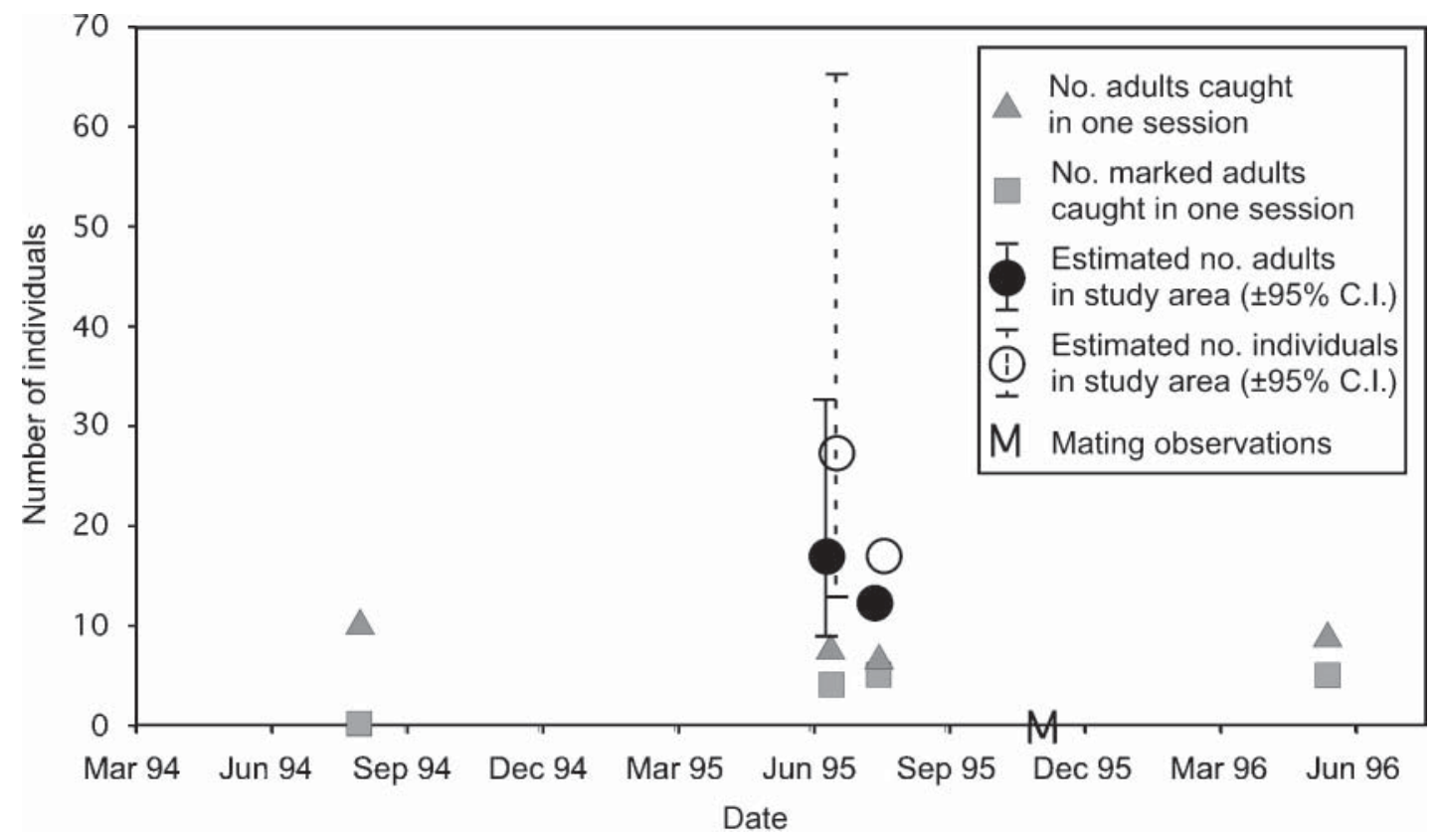

Fig. 2 Results of the fossa mark-recapture study, which comprised four trapping sessions. 
(nine adults) gave a minimum density estimate of 0.11 adults $\mathrm{km}^{-2}$.

\section{Home range/density estimate}

We obtained frequent fixes on five males and five females. Male ranges overlapped substantially but female ranges, being exclusive (Fig. 3), could be used to generate an independent density estimate. Two females were consistently located, allowing home range estimation, but in one case only 22 fixes were acquired (the home range surrounded by the dashed line in Fig. 3). For the other, 46 fixes were acquired, giving a home range of $9.2 \mathrm{~km}^{2}$ that was consistent with other, incomplete home ranges (Fig. 3). Assuming this to be a typical home range, female density was 0.11 female $\mathrm{km}^{-2}$. On the basis of the 1:1 sex ratio adult (male + female) density should be twice the adult female density, i.e. 0.22 adults $/ \mathrm{km}^{-2}$.

\section{Discussion}

The population density estimate of 0.18 adults $/ \mathrm{km}^{-2}$, or 0.26 individuals $\mathrm{km}^{-2}$, from our mark-recapture data was consistent with our independent estimate, from limited home range data, of 0.22 adults $/ \mathrm{km}^{-2}$.

\section{Population density}

There are divergent predictions of fossa population density based on its body mass. In view of the 1:1 sex ratio found in this study, we take mean fossa body mass as half of the sum of the mean body masses of the adult male and adult female respectively: $6.75 \mathrm{~kg}$ (Hawkins, 1998; this study). On the basis of data from 25 species of Carnivora from around the world, with a range of diets, Carbone \& Gittleman (2002) predicted a density of 0.37 individuals $\mathrm{km}^{-2}$, which is relatively close to our estimate. Peters (1983) alternatively offers a prediction based on data from 63 species of tropical mammalian
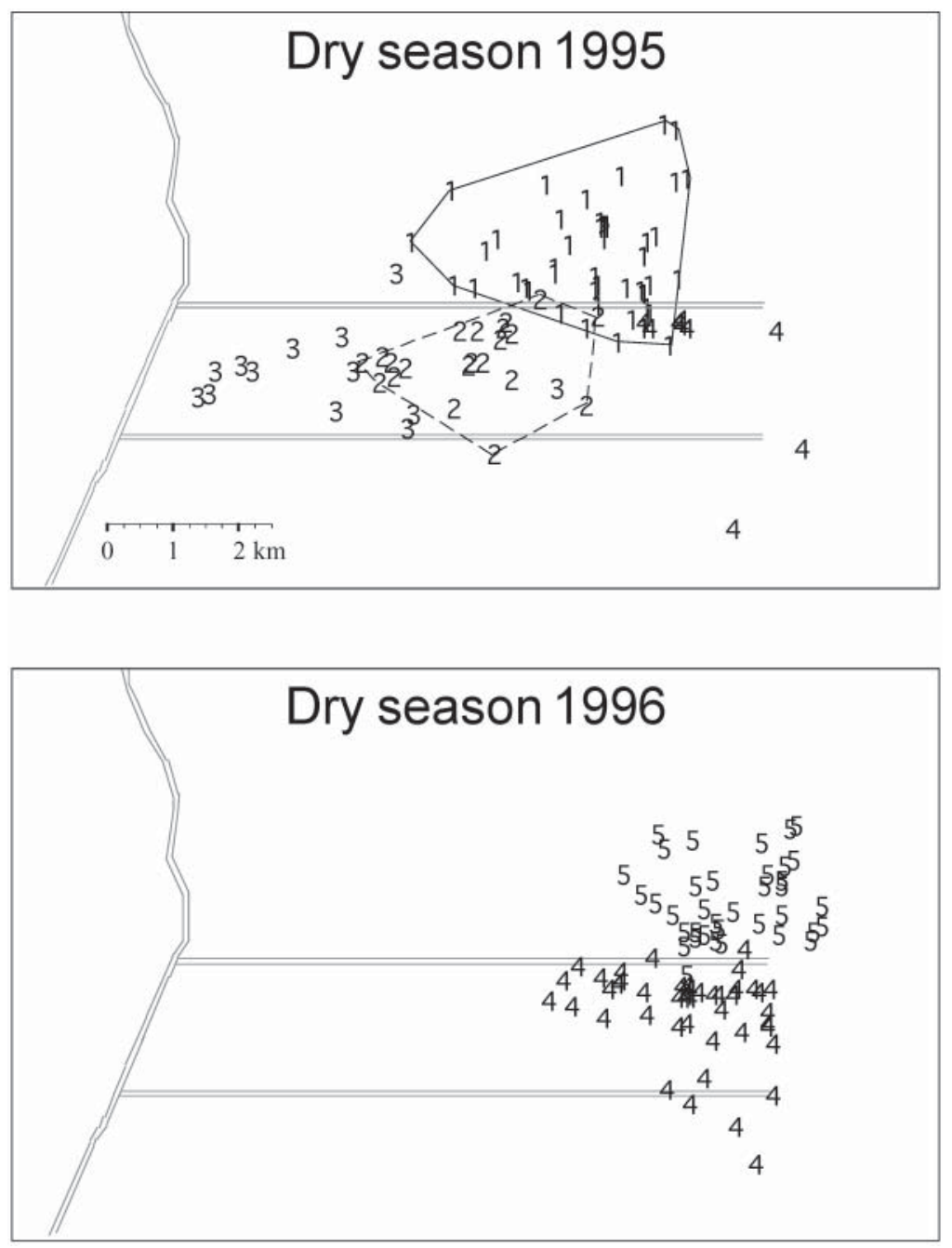

Fig. 3 Dry season location data obtained from five adult female fossas. Edges are drawn around a home range only when an animal could be located every time it was sought. All fixes were taken at a minimum of 8 hours apart. Parallel lines are major vehicle tracks. 
true carnivores, of 1.24 individuals $\mathrm{km}^{-2}$. The larger sample size and focus on tropical, true carnivores may make Peters' prediction more appropriate for the fossa. However, our estimate of 0.26 individuals $\mathrm{km}^{-2}$ corresponds with Peters' (1983) prediction for a tropical carnivorous mammal of over five times this mass. The difference between this prediction and our observation is surprising; Peters' model applies well to other tropical forest-dwelling mammalian carnivores. Ocelot Felis pardalis density, at 0.8 individuals $\mathrm{km}^{-2}$ (Emmons, 1987), is accurately predicted as 0.89 individuals $\mathrm{km}^{-2}$; forestdwelling leopard density Panthera pardus, at 0.07-0.11 individuals $\mathrm{km}^{-2}$ (Jenny, 1996), is relatively close to the predicted 0.16 individuals $\mathrm{km}^{-2}$, given the great variability in leopard body size. However, Carbone \& Gittleman's (2002) data may be more accurate, being mostly drawn from recent studies that may have benefited from newer techniques, and in covering multiple populations for the majority of species.

We have confidence in our estimate for several reasons. An assumption of the Jolly-Seber model is equal trappability of individuals. However, the trappability of any one individual must depend on the extent to which its home range overlaps with the trapping area, risking an underestimate. Gilbert (1973) showed that, where nearly all animals have a trappability of $>0.5$, this problem is negligible. Median trappability in our study was at this critical value, and the independent density estimate suggests that any inequality in trappability has not significantly affected the mark-recapture calculation. Moreover, direct observations of animals over a 2-week period of the mating season (Hawkins, 1998), at two sites within the area enclosed by traps, indicated that sampling was adequate. At the time of the observations (November 1995; Fig. 2), we had captured and ear-tagged $80 \%$ of the estimated adult population. Out of a median of 2.5 adults (interquartile range 2-5.5) observed each day, a median of 100\% (interquartile range $68.75-100 \%$ ) was ear-tagged (Hawkins, unpubl. data). This supports our assumption that there was no significant group of trap-shy animals that we never caught.

The fossa's relatively low density may also be explained by the high proportion of primates in its diet (Wilson et al., 1989; Rasolonandrasana, 1994; Overdorff \& Strait, 1995; Rasoloarison et al., 1995; Wright et al., 1997; Hawkins, 1998; Britt et al., 2001; Goodman, 2003). No other mammal specializes in primate predation to the same degree. The slow reproductive rate of primates may support only low densities of predators. Interspecific competition has been linked to low densities in other carnivores (Mills \& Gorman, 1997; Durant, 1998), but no carnivores with a similar diet exist in Madagascar.

\section{Threatened status}

According to our estimate of fossa population density, Menabe holds 336 adults. Between 1963 and 1993, deforestation at a rate of $33 \mathrm{~km}^{2}$ per year was recorded in Menabe (Tidd et al., 2001). Since then deforestation has continued at a much increased rate (J.E. Pinder \& J.C. Durbin, pers. comms). Extrapolating from the figures of Tidd et al. (2001), the region currently holds $1,870 \mathrm{~km}^{2}$ of forest, divided into three main fragments. The single protected area in Menabe, Andranomena, is only large enough to contain 12 adult fossas, but is extensively degraded. Our study area, Kirindy, is contiguous with Andranomena but is not a legally recognized protected area, and in isolation is only large enough to contain 18 adults. The true figures may be substantially less because of: (1) the region's fragmented state, which may isolate populations and subject individuals to fatal encounters with humans during chicken predation; (2) the quality of the forest, much of which is in a less pristine state than Kirindy (pers. obs., 1996); (3) escalation of legal and illegal logging in Menabe, which extended into Kirindy in 2001 (S. Sommer, pers. comm.).

There is, understandably, frequent pressure from wildlife managers to supply estimates of local and global population sizes from limited data (IUCN, 2001). Here, we attempt to provide such estimates, and identify sources of variation that are insufficiently understood for these estimates to be accurate. We argue that these estimates are most likely to be too high, indicating that Madagascar's protected areas may not cover a sufficient area to ensure the fossa's long-term survival. The exercise highlights the value of acquiring population estimates from other habitats.

The five largest forest protected areas in Madagascar known to contain fossas (J.L. MacKinnon, pers. comm.; Nicoll \& Langrand, 1989; CBSG, 2002) are listed in Table 1 , with estimates of their fossa populations, extrapolating

Table 1 The five largest forest protected areas in Madagascar known to be inhabited by fossas, and the number of fossas that they would hold if densities were the same as those found in Kirindy/CFPF, a western deciduous forest. Note that these are likely to be overestimates as protected areas contain a proportion of unsuitable habitat, and fossa density may be lower in eastern and southern forests.

\begin{tabular}{|c|c|c|}
\hline Protected Area & Area $\left(\mathrm{km}^{2}\right)^{*}$ & $\begin{array}{l}\text { Extrapolated size } \\
\text { of fossa population } \\
\text { (adult population) }\end{array}$ \\
\hline Masoala National Park & 2,300 & $598(414)$ \\
\hline Midongy-Sud National Park & 1,922 & $500(346)$ \\
\hline $\begin{array}{l}\text { Tsingy de Bemaraha National } \\
\text { Park \& Strict Nature Reserve }\end{array}$ & 1,520 & $395(274)$ \\
\hline Andohahela National Park & 760 & 198 (137) \\
\hline Kirindy-Mitea National Park & 722 & $188(130)$ \\
\hline
\end{tabular}

* From Parcs Nationaux de Madagascar (2001) 
from our density estimate. The 20 remaining forest protected areas known to hold fossas are each estimated to hold $<110$ adults, giving a total estimated protected population of $<2,500$ adults.

These figures may be overestimates for three reasons. Firstly, a protected area may include forest in several different states of degradation (e.g. up to one third of the original forest of Kirindy-Mitea National Park has been cleared; M. Nicoll, pers. comm.). Secondly, many protected areas are fragmented; both Andohahela National Park (Table 1) and Ranomafana National Park consist of several parcels; edge effects may reduce the number each fragment can support. Thirdly, fossas occupy a wide range of forest habitats, and their population densities may vary correspondingly. From the relative frequency of sightings of individuals and faeces (A.F.A. Hawkins, pers. comm.; Schreiber et al., 1989), and from the low trapping rates found in rainforest (L. Dollar, pers. comm.), the dry deciduous forests of Menabe and the Ankarana Special Reserve appear to hold dramatically higher densities of fossas than most other areas. An alternative explanation is that fossas are simply more cryptic and less trappable in humid conditions. During the wet season in Kirindy radio-collared fossas were rarely seen, were difficult to trap, they travelled shorter daily distances and their scats degenerated within a few hours (Hawkins, 1998). In rainforests, fossas were less apparent because of their more arboreal behaviour (J. Powzyk, pers. comm.). Nevertheless, we would expect higher densities of fossas in dry forests because higher densities of their primate prey have been found in this habitat (Ganzhorn et al., 2003).

If densities in other forest types are lower than in Kirindy, it is possible that no protected area holds a viable population of fossas. Data were insufficient for a Population Viability Analysis, but for little known species, a Minimum Viable Population size of 500 is a commonly used rule of thumb (Thomas, 1990), though this value is the subject of debate (Nunney \& Campbell, 1993; Franklin \& Frankham, 1998a, b; Lynch \& Lande, 1998). Our estimate suggests that only two protected areas hold 500 or more fossas (Table 1). It is important to recognize that a non-viable population will not disappear immediately. The extinction debt (Tilman et al., 1994) resulting from forest fragmentation may take many years to pay (Cowlishaw, 1999). Brooks et al. (1999) found that a tropical forest fragment typically takes 50 years to lose half the bird species that it is eventually likely to lose as a result of the fragmentation. Fossa populations in the other protected areas may be currently maintained through their connection with populations in adjacent forest that, being unprotected, could be destroyed. Even if edge effects arising from human encounters (Woodroffe \& Ginsberg, 1998) are not severe enough to bring about population extinction, isolation of these protected populations through physical barriers or substantial areas of unsuitable habitat may constitute a significant risk of extinction within 100 years.

The above discussion has followed the assumption that fossas are forest-dependent. Some evidence for flexibility of diet and habitat choice was provided by Goodman et al. (1997): their analysis of 20 fossa scats from above the treeline on the Andringitra Massif found 10\% of prey items to be invertebrates. However, some prey items recorded were species not found above the treeline, suggesting that the fossa does not subsist entirely from prey caught outside forested areas. Further work to explore the fossa's use of degraded and non-forested areas would be valuable in advising managers whether forested habitat corridors are necessary to link fossa populations in protected areas.

\section{Conservation recommendations}

We strongly recommend that conservation managers enlarge Madagascar's protected areas, or at least link them with corridors; we thus endorse the plans to do so of Madagascar's Association for the Management of protected areas (Parcs Nationaux de Madagascar). The fossa is found in forests throughout Madagascar, yet populations in all but the largest fragments may be at risk. A pragmatic aim, corresponding with current conservation work, would be to maintain a series of protected areas each sufficient to support at least short-term viable fossa populations (i.e. at least 100 individuals, Thomas, 1990), whilst continuing to encourage sustainable use of unprotected forests. Our study suggests that such populations require protected areas of at least $555 \mathrm{~km}^{2}$. No matter how well protected, smaller areas cannot ensure the preservation of an intact ecosystem unless connected to other suitable habitat. Protected areas of at least $2,000 \mathrm{~km}^{2}$ are preferable, to protect a potential population of 500 individuals. Masoala National Park, Madagascar's largest protected area, is the only one to have been designed on the basis of its resident species' needs (Kremen et al., 1999). Given Madagascar's current deforestation rate (Dufils, 2003), and despite the best efforts of many conservation organizations, the possibility remains that in a few decades the island's remaining forests may be confined to the few protected areas that have been adequately financed and managed for effective protection.

Our work suggests that the requirements of tropical forest carnivores may be underestimated. Whilst tigers and jaguars are relatively well studied, most of the smaller tropical carnivore species are little known and typically regarded as undemanding of area (Ginsberg, 2001). Their requirements must be verified and met if intact tropical forest ecosystems are to endure. Recently 
developed techniques for establishing these species' population densities (Gese, 2001) make this a realistic demand.

\section{Acknowledgements}

We thank the Commission Tripartite of the Malagasy Government, the Université d'Antananarivo and the Département des Eaux et Forêts for permission to work in Madagascar, our numerous field assistants, in particular Rabeantoandro Zoelisoa, Rasamison Aimé, Ioan Fazey and Neil Holmes, and colleagues for comments on earlier drafts, including Frank Hawkins and Simon Thirgood.

\section{References}

Albignac, R. (1973) Mammiferes Carnivores. Faune de Madagascar. ORSTOM, CNRS, Paris, France.

Britt, A., Welch, C. \& Katz, A. (2001) The impact of Cryptoprocta ferox on the Varecia $v$. variegata reinforcement project at Betampona. Lemur News, 6, 35-37.

Brooks, T.M., Pimm, S.L. \& Oyugi, J.O. (1999) Time lag between deforestation and bird extinction in tropical forest fragments. Conservation Biology, 13, 1140-1150.

Carbone, C. \& Gittleman, J.L. (2002) A common rule for the scaling of carnivore density. Science, 295, 2273-2276.

CBSG (Conservation Breeding Specialist Group) (2002) Evaluation et Plans de Gestion pour la Conservation (CAMP) de la Faune de Madagascar: Lémuriens, autres Mammiferres, Reptiles et Amphibiens, Poissons d'Eau douce et Evaluation de la Viabilité des Populations et des Habitats de Hypogeomys antimena (Vositse). Conservation Breeding Specialist Group (IUCN/ Species Survival Commission), Apple Valley, USA.

Cowlishaw, G. (1999) Predicting the pattern of decline of African primate diversity: an extinction debt from historical deforestation. Conservation Biology, 13, 1183-1193.

Crooks, K.R. \& Soulé, M.E. (1999) Mesopredator release and avifaunal extinctions in a fragmented system. Nature, 400, 563-566.

Dice, L.R. (1938) Some census methods for mammals. Journal of Wildife Management, 2, 119-130.

Dufils, J.-M. (2003) Remaining forest cover. In The Natural History of Madagascar (eds S.M. Goodman \& J.P. Benstead), pp. 88-96. The Universty of Chicago Press, Chicago, USA.

Durant, S.M. (1998) Competition refuges and coexistence: an example from Serengeti carnivores. Journal of Animal Ecology, 67, 370-386

Emmons, L.H. (1987) Comparative feeding ecology of felids in a neotropical rainforest. Behavioral Ecology and Sociobiology, 20, 271-283.

Estes, J.A. \& Duggins, D.O. (1995) Sea otters and kelp forests in Alaska - generality and variation in a community ecological paradigm. Ecological Monographs, 65, 75-100.

Fanshawe, J.H., Frame, L.H. \& Ginsberg, J.R. (1991) The wild dog: Africa's vanishing carnivore. Oryx, 25, 137-146.

FAO (Food and Agriculture Organization) (2001) Global Forest Resources Assessment 2000 - Main Report. FAO Forestry Paper 140. Http://www.fao.org/forestry/fo/fra/main/index.jsp [accessed 24 September 2004]
Franklin, I.R. \& Frankham, R. (1998a) How large must populations be to retain evolutionary potential? Animal Conservation, 1, 69-70.

Franklin, I.R. \& Frankham, R. (1998b) Response to Lynch \& Lande. Animal Conservation, 1, 73 .

Ganzhorn, J.U., Ganzhorn, A.W., Abraham, J.P., Andriamanarivo, L. \& Ramananjatovo, A. (1990) The impact of selective logging on forest structure and tenrec populations in western Madagascar. Oecologia, 84, 126-133.

Ganzhorn, J.U., Klaus, S., Ortmann, S. \& Schmid, J. (2003) Adaptations to seasonality: some primate and non-primate examples. In Primate Life Histories and Socioecology (eds P.M. Kappeler \& M.E. Pereira), pp. 132-148. University of Chicago Press, Chicago, USA.

Ganzhorn, J.U., Rakotosamimanana, B., Hannah, L., Hough, J., Iyer, L., Olivieri, S., Rajaobelina, S., Rodstrom, C. \& Tilkin, G. (1997) Priorities for biodiversity conservation in Madagascar. Göttingen: Primate Report, 48-1, 1-81.

Ganzhorn, J.U. \& Sorg, J.-P. (eds) (1996) Ecology and economy of a tropical dry forest in Madagascar. Primate Report, 46, 1 .

Gese, E.M. (2001) Monitoring of terrestrial carnivore populations. In Carnivore Conservation (eds J.L. Gittleman, S.M. Funk, D.W. Macdonald \& R.K. Wayne), pp. 372-396. Cambridge University Press, Cambridge, UK.

Gilbert, R.O. (1973) Approximations of the bias in the Jolly-Seber capture-recapture model. Biometrics, 29, 501-526.

Ginsberg, J.R. (2001) Setting priorities for carnivore conservation: what makes carnivores different? In Carnivore Conservation (eds J.L. Gittleman, S.M. Funk, D.W. Macdonald \& R.K. Wayne), pp. 498-523. Cambridge University Press, Cambridge, UK.

Goodman, S.M. (2003) Predation on lemurs. In The Natural History of Madagascar (eds S.M. Goodman \& J.P. Benstead), pp. 1221-1227. The University of Chicago Press, Chicago, USA.

Goodman, S.M., Langrand, O. \& Rasolonandrasana, B.P.N. (1997) The food habitats of Cryptoprocta ferox in the high mountain zone of the Andringitra Massif, Madagascar (Carnivora, Viverridae). Mammalia, 61, 185-192.

Green, G.M. \& Sussman, R.W. (1990) Deforestation history of the eastern rainforests of Madagascar from satellite images. Science, 248, 212-215.

Harris, S., Cresswell, W.J., Forde, P.G., Trewhella, W.J., Woollard, T. \& Wray, S. (1990) Home-range analysis using radio-tracking data - a review of problems and techniques particularly as applied to the study of mammals. Mammal Review, 20, 97-123.

Hawkins, C.E. (1998) Behaviour and ecology of the fossa, Cryptoprocta ferox (Carnivora, Viverridae) in a dry deciduous forest, western Madagascar. PhD thesis, University of Aberdeen, Aberdeen, UK.

Hawkins, C.E. (2003) Cryptoprocta ferox, fossa, fosa. In The Natural History of Madagascar (eds S.M. Goodman \& J.P. Benstead), pp. 1360-1363. The University of Chicago Press, Chicago, USA.

IUCN (2001) IUCN Red List Categories and Criteria Version 3.1. IUCN, Gland, Switzerland and Cambridge, UK.

IUCN (2003) 2003 IUCN Red List of Threatened Species. IUCN, Gland, Switzerland [http:/ / www. redlist.org, accessed 27 September 2004].

Jenny, D. (1996) Spatial organization of leopards (Panthera pardus) in Taï National Park, Ivory Coast: is rainforest habitat a 'tropical haven'? Journal of Zoology, 240, 427-440.

Jolly, G.M. (1965) Explicit estimates from capture-recapture data with both death and immigration - stochastic model. Biometrika, 52, 225-247. 
Kenward, R.E. (1985) Ranging behaviour and population dynamics in grey squirrels. In Behavioural Ecology. Ecological Consequences of Adaptive Behaviour (eds R.M. Sibly \& R.H. Smith), pp. 319-330. Blackwell Scientific Publications, Oxford, UK.

Krebs, C.J. (1966) Demographic changes in fluctuating populations of Microtus californicus. Ecological Monographs, 36, 239-273.

Kremen, C., Razafimahatratra, V., Guillery, R.P., Rakotomalala, J., Weiss, A. \& Ratsisompatrarivo, J.-S. (1999) Designing the Masoala National Park in Madagascar based on biological and socioeconomic data. Conservation Biology, 13, 1055-1068.

Lynch, M. \& Lande, R. (1998) The critical effective size for a genetically secure population. Animal Conservation, 1, 70-72.

Manly, B.F.J. (1984) Obtaining confidence limits on parameters of the Jolly-Seber model for capture-recapture data. Biometrics, 40, 749-758.

McLaren, B.E. \& Peterson R.O. (1994) Wolves, moose, and treerings on Isle Royale. Science, 266, 1555-1558.

Mills, M.G.L. \& Gorman, M.L. (1997) Factors affecting the density and distribution of wild dogs in the Kruger National Park. Conservation Biology, 11, 1397-1406.

Nicoll, M.E. \& Langrand, O. (1989) Révue de la conservation et des aires protégées. WWF, Gland, Switzerland.

Nunney, L. \& Campbell, K.A. (1993) Assessing minimum viable population size - demography meets population genetics. Trends in Ecology \& Evolution, 8, 234-239.

Overdorff, D.J. \& Strait, S.G. (1995) Life-history and predation in Eulemur rubriventer in Madagascar. American Journal of Physical Anthropology, suppl. 20, 156.

Pace, M.L., Cole, J.J., Carpenter, S.R. \& Kitchell, J.F. (1999) Trophic cascades revealed in diverse ecosystems. Trends in Ecology \& Evolution, 14, 483-488.

Parcs Nationaux de Madagascar (2001) Plan de Gestion du Réseau National des Aires Protégées de Madagascar. Parcs Nationaux de Madagascar, Antananarivo, Madagascar.

Peters, R.H. (1983) The Ecological Implications of Body Size. Cambridge University Press, Cambridge, UK.

Rabinowitz, D. (1981) Seven forms of rarity. In The Biological Aspects of Rare Plant Conservation (ed. H. Synge), pp. 205-217. Wiley, Chichester, UK.

Rasoloarison, R.M., Rasolonandrasana, B.P.N., Ganzhorn, J.U. \& Goodman, S.M. (1995) Predation on vertebrates in the Kirindy Forest, western Madagascar. Ecotropica, 1, 59-65.

Rasolonandrasana, B.P.N. (1994) Contibution à l'étude de l'alimentation de Cryptoprocta ferox Bennett (1833) dans son milieu naturel. D.E.A. thesis, Université d'Antananarivo, Antananarivo, Madagascar.

Schaller, G.B. (1996) Introduction: carnivores and conservation biology. In Carnivore Behaviour, Ecology, and Evolution, Volume 2 (ed. J.L. Gittleman), pp. 1-10. Cornell University Press, Ithaca, USA.

Schmitz, O.J., Hambäck, P.A. \& Beckerman, A.P. (2000) Trophic cascades in terrestrial systems: a review of the effects of carnivore removal on plants. American Naturalist, 155, 141-153.
Schreiber, A., Wirth, R., Riffel, M. \& Van Rompaey, H. (1989) Weasels, Civets, Mongooses, and their Relatives: An Action Plan for the Conservation of Mustelids and Viverrids. IUCN, Gland, Switzerland.

Seber, G.A.F. (1965) A note on the multiple-recapture census. Biometrika, 52, 249-259.

Sih, A., Crowley, P., McPeek, M., Petranka, J. \& Strohmeier, K. (1985) Predation, competition, and prey communities: a review of field experiments. Annual Review of Ecology and Systematics, 16, 269-311.

Smith A.P., Horning, N. \& Moore, D. (1997) Regional biodiversity planning and lemur conservation with GIS in Western Madagascar. Conservation Biology, 11, 498-512.

Soulé, M.E. (1987) Viable Populations for Conservation. Cambridge University Press, Cambridge, UK.

Thomas, C.D. (1990) What do real populations tell us about minimum viable population sizes? Conservation Biology, $\mathbf{4}$, 324-327.

Tidd, S.T., Pinder, J.E. \& Ferguson, G.W. (2001) Deforestation and habitat loss for the Malagasy flat-tailed tortoise from 1963 through 1993. Chelonian Conservation and Biology, 4 , 59-65.

Tilman, D., May, R.M., Lehman, C.L. \& Nowak, M.A. (1994) Habitat destruction and the extinction debt. Nature, 371, 65-66.

Wilson, J.M., Stewart, P.D., Ramangason, G.S., Denning, A.M. \& Hutchings, M.S. (1989) Ecology and conservation of the crowned lemur, Lemur coronatus, at Ankarana, N. Madagascar - with notes on Sanford's lemur, other sympatrics and subfossil lemurs. Folia Primatologica, 52, 1-26.

Woodroffe, R. \& Ginsberg, J.R. (1998) Edge effects and the extinction of populations inside protected areas. Science, 280, 2126-2128.

Wright, P.C., Heckscher, S.K. \& Dunham, A.E. (1997) Predation on Milne-Edward's sifaka (Propithecus diadema edwardsi) by the fossa (Cryptoprocta ferox) in the rain forest of southeastern Madagascar. Folia Primatologica, 68, 34-43.

\section{Biographical sketches}

Clare Hawkins specializes in carnivore conservation ecology, but has also worked on the conservation and ecology of fruit bats in Madagascar and on wildlife disease epidemiology. She is currently studying the conservation and management of marsupial carnivore populations in Tasmania, Australia.

Paul Racey researches the reproductive ecology and conservation of a range of mammals around the world, in particular Scotland and Madagascar, specializing in bats. Current projects focus on acoustic communication, genetic substructuring and the conservation and management of European and tropical bats. 